\title{
Neonatal Hypothermia: Mothers' Knowledge and Practice at a Provincial Hospital in Rwanda
}

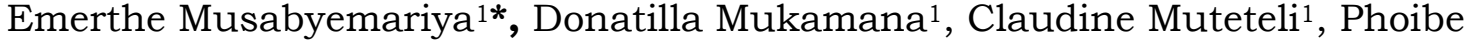 \\ Uwizeyimana $^{2}$, Geldine Chironda1, 3, 4, Lakshmi Rajeswaran 1,3 \\ ${ }^{1}$ School of Nursing and Midwifery, College of Medicine and Health Sciences, University of \\ Rwanda, Kigali, Rwanda \\ ${ }^{2}$ Butare University Teaching Hospital, Huye, Rwanda \\ ${ }^{3}$ Rory Meyers College of Nursing, New York University, USA \\ ${ }^{4}$ School of Nursing and Public Health, College of Health Sciences, University of KwaZulu-Natal, \\ Durban, South Africa
}

*Corresponding author: Emerthe Musabyemariya. School of Nursing and Midwifery, College of Medicine and Health Sciences, University of Rwanda, Rwamagana Campus, Eastern Province, Rwanda. Email: musabyemrita@gmail.com.

\begin{abstract}
Background

Globally, 2.5 million neonates die each year from hypothermia. The World Health Organization (WHO) considers neonatal hypothermia as a decrease of axillary temperature in infants below $36.5^{\circ}$ Celsius. New mothers, or the nearest caregivers, should be aware that hypothermia is a newborn danger sign, in order to apply best practices regarding neonatal hypothermia prevention to reduce subsequent mortality.
\end{abstract}

\section{Objective}

To assess mothers' knowledge and practice of neonatal hypothermia at a selected provincial hospital in Rwanda.

\section{Methods}

A cross-sectional study design and convenience sampling method were used to select 161 mothers with living babies. Data were collected using a structured questionnaire. Descriptive and inferential statistics were used to analyze data.

\section{Results}

About $97 \%$ of mothers had inadequate knowledge, and the majority $(83 \%)$ had inadequate neonatal hypothermia practices. Predictor variables for knowledge were ANC attendance $(\mathrm{OR}=1.884,95 \% \mathrm{CI}=1.675-2.565, \mathrm{p}=0.042)$ and secondary educational level $(\mathrm{OR}=1.787,95 \%$ $\mathrm{CI}=1.521-2.187, \mathrm{p}=0.032)$. Practice was significantly associated with educational level (OR=1.787, 95\% CI=1.521-2.187, $\mathrm{p}=0.032)$.

\section{Conclusion}

There is a need to increase a mother's evidence-based practice of neonatal hypothermia. This condition unchecked leads to high-risk life-threatening complications. Prevention should emphasize on observed gaps to decrease deaths related to neonatal hypothermia.

Rwanda J Med Health Sci 2020;3(2):152-166

Keywords: Neonatal hypothermia, postpartum mothers, knowledge, postnatal care.

\section{BACKGROUND}

Worldwide, neonatal hypothermia constitutes a substantial leading cause of neonatal death and health impairment among neonates regardless of climates.[1] A study conducted in Ethiopia argued that in low and middle income countries (LMIC) and Sub-Sahara region, neonatal hypothermia was highly prevalent.[2] Data from a Cochrane systematic review of literature concerning LMIC reported hypothermia prevalence rates that varied from $8 \%$ to $85 \%$ in Guinea-Bissau, Zimbabwe and in India these rates oscillated from $11 \%$ to $92 \% .[1,2,3]$ In West African sub-regions a prevalence rate of $62 \%$ at the point of admission was reported; Ethiopia and 
Nigeria accounted a prevalence of hypothermia ranging to $69.8 \%$ and $90.9 \%$, respectively.[2]

In Rwanda, 2014 annual health statistics reported $77 \%$ cases of hypothermia admitted in NICU.[4] Although current data are not available, several studies highlight the importance of the burden of neonatal hypothermia in both resources poor and resource-rich settings and across all climates.[1,2, $5,6]$ Moreover all neonates are prone to hypothermia due to immaturity of thermoregulation center.[5] Mothers play a significant role in newborns' life and their level of knowledge would help the neonate to survive from dangerous conditions, notably hypothermia.[7] Therefore, mothers or other close caregivers of neonates must be knowledgeable about thermal care such as skin-to-skin contact (SSC), delaying bath and breastfeeding.[5]

Neonatal hypothermia is characterized by clinical features owing to environmental, physiological factors, or metabolic changes affecting all vital systems. Hence a hypothermic baby appears lethargic with poor feeding, cold extremities, and bradycardia with respiratory distress and tachypnea ensue.[5] Numerous studies underlining the magnitude of the problem state that a $1^{0} \mathrm{C}$ decline in body temperature exposes the neonate to die by 80\%.[2,3] Hypothermia should be prevented through strict observance of the chain of warm that includes keeping the baby and the mother together.[6] Gaps occur when the neonate is not initially given SSC with the mother immediately in the delivery room, transferred to advanced care, or discharged from the hospital; hence this chain is interrupted. [5, 6] Therefore, healthcare providers (HCPs) have to equip mothers with adequate knowledge and practices regarding neonatal hypothermia, beginning immediately after birth.[10] SSC/ KMC and breastfeeding should be encouraged even for term or stable preterm neonates.[7] These two technics remain genuine strategies in producing natural heat and hold numerous other benefits that will enhance further positive outcomes for the growing neonate.[1]

The paucity of Rwandan literature on this topic was a big challenge to the researcher as currently, there was limited evidence addressing neonatal hypothermia. The grand majority of articles were from Asia, [5,6,7,11,12,13] and other articles were from Africa. $[2,8,11,14]$ Data from high income countries are not accessible. Assessing mothers' knowledge and providing constant health education in terms of neonatal hypothermia, should assist in preventing or reducing cases of hypothermia or readmission to the NICU for this problem. The present study assessed mothers' knowledge and practices regarding neonatal hypothermia, as they are typically the primary caregivers responsible for recognizing changes in the neonate for timely interventions and management before complications arise.

\section{METHODS}

\section{Design}

A quantitative approach with a descriptive crosssectional study design was used to assess mothers' knowledge and practice of neonatal hypothermia. Data were collected from February 12 to March 15, 2019.

\section{Study setting}

Data were collected at a selected provincial hospital located in Rwamagana District, Eastern Province, in Rwanda. The district consists of government owned 14 health centers and 17 health posts, two private clinics with one prison dispensary. The population of the study area consists of 369,671 inhabitants, including 216,064 women $(78,398$ of reproductive age) and 153,607 men. The site was chosen because the provincial hospital receives a high number of pregnant women attending the antenatal clinic.

\section{Participants' recruitment Inclusion criteria and Exclusion criteria}

In this study, the mothers with neonates in maternity and neonatology wards who delivered at the selected sites and willing to participate were included. Mothers with very sick neonates and not willing to participate were excluded from the study.

\section{Sample size}

The sample size of the study was calculated based on the number of delivering mothers who attended the selected provincial hospital. The records of delivering mothers from January to December 2018 accounted for 3,246 mothers of live births. To calculate the monthly estimate, the researchers divided 3246 mothers of live births by 12 to get the monthly estimate total population of 270.5 which translate to approximately 271 mothers. The target sample size of the study was calculated using the Taro Yamane formula [15] with a confidence interval of $95 \%$ and a margin error of $5 \%$ as the following:

$$
\mathrm{n}=\frac{\mathrm{N}}{1+\mathrm{N} \cdot \mathrm{e}^{2}}
$$

$\mathrm{n}=$ sample size,$\quad \mathrm{N}=$ number of total population, $\mathrm{e}=$ value of accepted error. 


$$
\mathrm{n}=\frac{271}{1+271 \cdot\left(0.05^{2}\right)}=161
$$

Therefore, the sample size used for the study was 161 mothers with live born neonates.

\section{Sampling strategy}

A convenience sampling method was used in this study. It is a non-probability sampling technique which was chosen because the participants were selected due to their accessibility and proximity to the researcher. [15] This method was most appropriate as mothers in the post-partum period stay only for 24 hours in the hospital.

\section{Research tool}

An adopted tool was used to collect data after permission was obtained from the authors. The permission of the questionnaire used in the study was obtained by email on September 11, 2018. [3] The research tool was modified using other aspects from in-depth literature to suit the context of Rwanda. Data were collected using an interview technique whereby mothers were asked questions, and the researcher documented their answers.

The tool included three sections, namely, sociodemographic characteristics with obstetrical factors, mothers' knowledge, and mothers' practices regarding neonatal hypothermia. Section one included sociodemographic characteristics (6 items) with attributes namely age, educational level, religion, marital status, and occupation both for mothers and husband; in addition, the questionnaire reflected on obstetrical factors (3 items) such as number of antenatal care (ANC) visits, gender and chronologic age of the baby.

The second section included mothers' knowledge (15 Items) related to the definition, meaning, signs, prevention, consequences of neonatal hypothermia. The responses for variables of knowledge were as follows: 1: Correct answer, 0 for the incorrect answer. The highest and the least attainable score for knowledge was 15 and zero respectively. To characterize the level of knowledge, the scores were ranged in 2 categories namely adequate and inadequate. [12] Dividing the attained score on this section by the maximum possible attainable score (15) and multiplying by a hundred to come up with a percentage calculated level of knowledge of 75 $100 \%$ as adequate and less than $74.9 \%$ as inadequate. A score of 11 and below translated to $74.9 \%$ and 12 to 15 translated to 75 to $100 \%$.
The third section consisted of mothers' practices towards prevention of neonatal hypothermia (10 items) which included temperature measurement, bathing the baby, drying the baby, maintaining the baby warm, keeping baby and mothers together, breastfeeding, skin to skin technic and care during transport. The responses for practice questions were as follows: 1: correct answer (reliable with WHO chain of warm); 0: incorrect answer (not in agreement with WHO chain of warm).

The highest and lowest attainable scores for practice was 10 and zero respectively. To establish the level of practice, the scores were ranked into two categories namely good and poor practice. Dividing the attained score on this section by the maximum possible attainable score (10) and multiplying by a hundred to come up with a percentage calculated level of practice of $70-100 \%$ as good and less than $70 \%$ as poor. A score of 7 to 10 translated to 70 to $100 \%$ and below 7 translated to less than $70 \%$.

\section{Validity and reliability of the tool}

Inclusion of items from the adopted tool and literature enhanced the content validity of the tool. A panel of experts in the academic and clinical field were used to check if the tool has included all the aspects of knowledge and practice related to the context of Rwanda. Restructuring the instrument into 3 sections enhanced the face validity of the research tool. To validate the content of the instrument for data collection in this study, the researchers linked the objectives of the study with aforementioned sections of the questionnaire.

Translating the research tool from English to Kinyarwanda ensured collection of reliable data, free from misinterpretation. Back translated of the tool was done to ensure that no meaning was distorted during the translation process. A pretesting was conducted on 20 mothers having the same characteristics as the target population and no ambiguities and inconsistencies were found in the tool. For internal consistency, SPSS generated revealed a Cronbach's Alpha coefficient of 0.88 indicating that the tool was a reliable measure of variables under study.

\section{Data collection}

Participants were met in the postpartum ward where all delivered mothers, including those who had their babies in neonatology, were gathered. The unit manager introduced the investigator to mothers to ensure their safety and offered a private room to meet each mother fulfilling inclusion criteria and mostly willing to participate in the study. 
Data collection occurred after the medical morning rounds. The names and bed numbers were made available to the researcher. The mothers completed the questionnaire within about 20 minutes.

\section{Data analysis}

The data collected from participants were cleaned, coded and entered into SPSS software version 21(IBM SPSS, 2012). Sociodemographic and obstetrical data were summarized using descriptive statistics namely frequencies and percentages. Variables measuring the knowledge and practice of mothers were analyzed using descriptive statistics in the form of frequencies and percentages. The level of knowledge and practice was calculated using total scores and the highlighted scales in the research tool with data interpretation in terms of means, mode and median. The presentation was also done in frequencies, and percentages. Factors associated with knowledge and practice of mothers were examined using Chi-square test followed by multivariate logistic regression on variables that showed significant association. A p-value $\leq 0.05$ was considered statistically significant.

\section{Ethical considerations}

Permission to conduct this study was obtained from the Institutional Review Board (IRB) of the University of Rwanda, College of Medicine and Health Sciences, and Rwamagana Provincial Hospital. Caution was taken to protect the violation of participants' rights during the study. All interviews with participants were conducted in a private area which was designated for this purpose at the study facilities. To ensure confidentiality, all participants were given a study ID number on enrolment with no identifying information entered into the databases.

All study bases were password protected, securely stored and only transmitted through password protected email. However, anonymity was not achieved because the researcher employed face-toface interviews with all the participants for the purposes of clarification and verification of the interview data. The purpose of the study was explained to potential subjects before obtaining their informed consent and their voluntary willingness to participate in the study was sought. The subjects were assured that there were no risks involved in participating in the study. Subjects were informed of their freedom to withdraw from the study, should they wish to do so at any stage, without affecting their positive therapeutic relationships with the staff involved in their care program. For this study, participants who were willing to participate, a consent form was signed which indicated acceptance and the forms were not attached to the instruments. 


\section{RESULTS}

\section{Sociodemographic and obstetrical characteristics of participants}

Table1. Sociodemographic characteristics of participants $(n=161)$.

\begin{tabular}{ll}
\hline Variables & $\mathbf{n}(\mathbf{\%})$ \\
\hline Age (years) & \\
$\leq 20$ & $18(11.2)$ \\
$21-30$ & $75(46.6)$ \\
$31-40$ & $66(41.0)$ \\
Z41 & $2(1.2)$ \\
Education level & \\
No education & $11(6.8)$ \\
Primary education & $125(77.6)$ \\
Secondary education & $25(15.5)$ \\
Marital status & \\
Married & $114(70.8)$ \\
Single & $26(16.1)$ \\
Separated/Divorced & $21(13.0)$ \\
Religion & \\
Catholic & $84(52.2)$ \\
Protestant & $18(12.2)$ \\
Seventh Day Adventists & $12(7.5)$ \\
Muslims & $47(29.2)$ \\
Mother's occupation & \\
Farming & $95(59.0)$ \\
State \& private employed & $4(2.5)$ \\
Self-employed & $11(6.8)$ \\
Housewife & $36(22.4)$ \\
Not employed & $15(9.3)$ \\
Father's occupation & \\
Farming & $113(70.2)$ \\
State \& private employed & $26(16.1)$ \\
Self-employed & $22(13.7)$ \\
ANC attendance & \\
None & $15(9.3)$ \\
1 time & $30(18.6)$ \\
2-3 times & $104(64.6)$ \\
B and plus & $12(7.5)$ \\
Baby's age (days) & \\
1 & $20(12.4)$ \\
2 & $84(52.2)$ \\
3 & $53(32.9)$ \\
4 & $4(2.5)$ \\
Baby born at term & $152(94.4)$ \\
Yes & $9(5.6)$ \\
No & \\
Maby's gender & $74(46.0)$ \\
Female & \\
\hline & \\
\hline
\end{tabular}

Table 1 depicts the sociodemographic and obstetric data profile. The majority of participants (46.6\%) were aged between 21-30 years old, followed by those who were aged between 31 and 40 years $(41 \%)$. Most of the mothers were educated at the primary level $(77.6 \%)$, married $(70.8 \%)$, worked as farmers $(59 \%)$, and followed catholic religion $(52 \%)$. Husbands $(70.2 \%)$ were also 
farmers. Concerning obstetrical data, the majority of mothers (64.6\%) attended ANC visits $2-3$ times. The majority of neonates were female, term $(94.4 \%)$, and two days post-birth $(52.2 \%)$.

Information on neonatal hypothermia

Table 2. Information on neonatal hypothermia

\begin{tabular}{|c|c|}
\hline Variable & n (\%) \\
\hline \multicolumn{2}{|c|}{ Received information on neonatal hypothermia } \\
\hline Yes & $68(42.2)$ \\
\hline No & $93(57.8)$ \\
\hline \multicolumn{2}{|c|}{ Source of information on neonatal hypothermia } \\
\hline Parents & $9(5.6)$ \\
\hline Nurse or midwives & $154(94.4)$ \\
\hline
\end{tabular}

With regards to information, more than half $(57.7 \%)$ of participants reported that they did not receive information. For those who received information, the majority, [94.1\%] got it from the midwife or the nurse (Table 2).

Mother's knowledge of hypothermia in neonates

Table 3. Mother's knowledge of hypothermia in neonates (n-161)

\begin{tabular}{lll}
\hline Assessment items & $\begin{array}{l}\text { Yes } \\
\mathbf{n}(\%)\end{array}$ & $\begin{array}{l}\text { No } \\
\mathbf{n}(\%)\end{array}$ \\
\hline $\begin{array}{l}\text { Hypothermia Knowledge } \\
\begin{array}{l}\text { Ability to recognize body temperature } \\
\text { Causes in newborn }\end{array}\end{array}$ & $43(26.7)$ & $118(73.3)$ \\
$\begin{array}{l}\text { Washing the baby immediately after birth } \\
\text { Covering the baby with a cold towel }\end{array}$ & $63(39.1)$ & $98(60.9)$ \\
$\begin{array}{l}\text { Lying the baby in a cold area } \\
\text { Lying the baby alone }\end{array}$ & $151(93.8)$ & $10(6.2)$ \\
Signs and symptoms & $142(88.2)$ & $19(11.8)$ \\
Cyanosis and cold extremities & $62(38.5)$ & $99(61.5)$ \\
$\begin{array}{l}\text { Poor feeding } \\
\text { Lethargy }\end{array}$ & $141(87.6)$ & $20(12.4)$ \\
Complications & $54(33.5)$ & $107(66.5)$ \\
$\begin{array}{l}\text { Dyspnea } \\
\text { Hypoglycemia }\end{array}$ & $54(33.5)$ & $107(66.5)$ \\
$\begin{array}{l}\text { Decrease in weight } \\
\text { Death }\end{array}$ & $60(37.3)$ & $101(62.7)$ \\
Prevention & $0(0.0)$ & $161(100.0)$ \\
No bathing immediately after birth & $0(0.0)$ & $161(100.0)$ \\
$\begin{array}{l}\text { Dry baby after bathing and wrap in warm clothe } \\
\text { Skin-to-skin contact }\end{array}$ & $125(77.6)$ & $36(22.4)$ \\
Early initiation of breastfeeding within the first 4 hours & & \\
\hline
\end{tabular}

Correct answers to the knowledge of neonatal hypothermia were presented in Table 3.

Over a quarter of participants $(26.7 \%)$ reported that they could recognize neonatal hypothermia from a temperature measurement. Regarding causes of hypothermia, (60.9\%) of mothers did not know that early bathing could cause hypothermia. Nearly all $(93.8 \%)$ responded correctly about covering the neonate with a cold towel; lying the baby in a cold area $(88.2 \%)$, whereas $(61.5 \%)$ did not know that lying the baby alone can cause hypothermia. About signs and symptoms of hypothermia, cyanosis, and cold extremities were answered correctly by $(87.6 \%)$ of mothers. 
In comparison (66.5\%) did not know that poor feeding and lethargy are signs and symptoms of hypothermia, and most of the mothers did not know complications of hypothermia. The majority $(87.0 \%)$ believed that drying the baby after bathing and wrapping the baby in warm clothe could prevent hypothermia. Nearly all (94.4\%) did not believe that SSC could prevent hypothermia, or believe that early initiation of breastfeeding within the first four hours can prevent hypothermia (88.2\%).

\section{Mothers' practice of neonatal hypothermia}

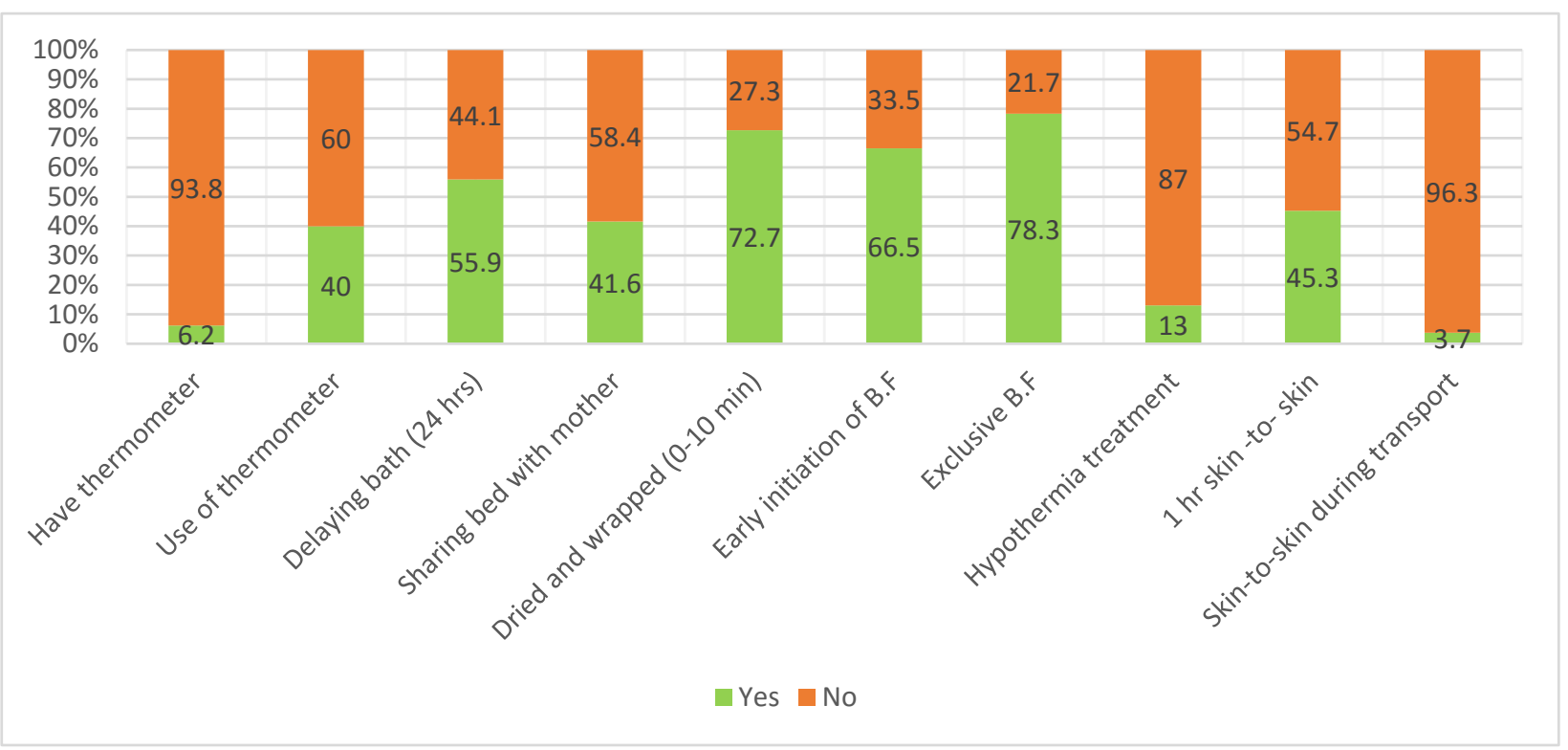

Figure 1. Mothers' practice towards neonatal hypothermia $(n=161)$

Regarding practices on thermal care, the majority $(93.8 \%)$ of mothers did not have a thermometer at home, or had a thermometer at home $(60.0 \%)$ and did not know how to use it (Figure 1). Concerning bathing the neonate, (55.9\%) know when to bath the neonate, and maintaining the baby's warm (58.4\%). The majority $(72.7 \%)$ reported the time of drying correctly and wrapping the neonate, whereas $(88.2 \%)$ did not know the best practice after washing the baby.

More than half of mothers (66.5\%) initiated breastfeeding soon after birth. However, over a half $(60.9 \%)$ also used formula when they thought they did not have enough colostrum. Furthermore, the majority (87.0\%) of mothers did not know SSC between mother and baby, and (54.7\%) did not know how long SSC should be practiced. Nearly all $(96.3 \%)$ did not know the best way to prevent heat loss if the neonate is transported to advanced care at home or specific treatment for a baby that gets cold at home (Refer to Figure 1). 


\section{Participants level of knowledge and practice regarding neonatal hypothermia}

Table 4. Participants' level of knowledge and practice regarding neonatal hypothermia $(\mathrm{n}=161)$

\begin{tabular}{|c|c|c|c|c|}
\hline $\begin{array}{l}\text { Knowledge } \\
\text { scores out of } 16\end{array}$ & $\begin{array}{c}\text { Knowledge score in } \\
\text { percentage }\end{array}$ & Frequency & $\begin{array}{c}\text { Level of } \\
\text { knowledge }\end{array}$ & $\begin{array}{l}\text { Measure of central } \\
\text { tendency. }\end{array}$ \\
\hline 3 & 19 & 10 & \multirow{6}{*}{$\begin{array}{l}\text { Inadequate: } \\
157(97 \%)\end{array}$} & \multirow{7}{*}{$\begin{array}{l}\text { Mean score: } 42 \% \\
\text { Median score: } 31 \% \\
\text { Mode: } 31 \% \\
\text { Minimum } \\
19 \% \\
\text { Maximum score: } \\
75 \%\end{array}$} \\
\hline 4 & 25 & 31 & & \\
\hline 5 & 31 & 56 & & \\
\hline 9 & 56 & 20 & & \\
\hline 10 & 63 & 14 & & \\
\hline 11 & 69 & 26 & & \\
\hline 12 & 75 & 4 & $\begin{array}{l}\text { Adequate: } \\
4(3 \%)\end{array}$ & \\
\hline $\begin{array}{ll}\text { Practice } & \text { score } \\
\text { out } 10 & \\
\end{array}$ & $\begin{array}{c}\text { Practice score in } \\
\text { percentage }\end{array}$ & Frequency & $\begin{array}{l}\text { Level of } \\
\text { practice }\end{array}$ & $\begin{array}{c}\text { Measure of central } \\
\text { tendencies. }\end{array}$ \\
\hline 0 & 0 & 6 & \multirow{7}{*}{$\begin{array}{l}\text { Poor } \\
\text { practice: } \\
133(83)\end{array}$} & \multirow{9}{*}{$\begin{array}{l}\text { Mean: } 46.8 \% \\
\text { Median:50\% } \\
\text { Mode: } 40 \% \\
\text { Minimum score: } 0 \% \\
\text { Maximum score } \\
: 80 \%\end{array}$} \\
\hline 1 & 10 & 5 & & \\
\hline 2 & 20 & 7 & & \\
\hline 3 & 30 & 18 & & \\
\hline 4 & 40 & 38 & & \\
\hline 5 & 50 & 32 & & \\
\hline 6 & 60 & 27 & & \\
\hline 7 & 70 & 18 & \multirow{2}{*}{$\begin{array}{l}\text { Good } \\
\text { practice: } \\
28(17 \%)\end{array}$} & \\
\hline 8 & 80 & 10 & & \\
\hline
\end{tabular}

Regarding knowledge scores, the minimum ranged from 3 to a maximum of 12 out of possible score of 16 which translate to a percentage score of $19 \%$ and $75 \%$ respectively. The mean, mode and median score was $6.76,5$ and 5 respectively. This translate to percentage mean score of $42 \%$ and $31 \%$ for both median and mode. Although $64(40 \%)$ of the participants scored above the mean, the level of knowledge on neonatal hypothermia based on the scale was inadequate in majority [15 7(97\%)] of the participants with only $4(3 \%)$ achieving adequate knowledge (Table 4).

Concerning the level of practice on prevention of neonatal hypothermia, the minimum ranged from 0 to a maximum of 8 out of possible score of 10 which translate to a percentage score of $0 \%$ and $80 \%$ respectively. The mean, mode and median score was $4.68,5$ and 4 respectively. This translate to percentage mean score of $47 \%$ and $50 \%$ for median and $40 \%$ mode. Although $87(54 \%)$ of the participants scored above the mean, the level of practice on prevention of neonatal hypothermia based on the scale was poor in majority [133(83\%)] of the participants with only $28(17 \%)$ exhibiting good practice behaviors (Table 4). 


\section{Association of knowledge and practice with sociodemographic characteristics}

Table 5. Association of knowledge and practice with sociodemographic characteristics

\begin{tabular}{|c|c|c|c|c|c|c|}
\hline \multirow{2}{*}{$\begin{array}{l}\text { Variables } \\
\text { Age (years) }\end{array}$} & \multicolumn{3}{|c|}{ Knowledge of Hypothermia } & \multicolumn{3}{|c|}{ Practice of Hypothermia } \\
\hline & $\begin{array}{l}\text { Adequate } \\
\text { n (\%) }\end{array}$ & $\begin{array}{l}\text { Inadequate } \\
\text { n }(\%)\end{array}$ & $\mathbf{p}$ & $\begin{array}{l}\text { Good } \\
\text { n(\%) }\end{array}$ & $\begin{array}{l}\text { Poor } \\
\text { n (\%) }\end{array}$ & $\mathbf{p}$ \\
\hline$\leq 20$ & $6(33.3)$ & $12(66.7)$ & 0.002 & $6(33.3)$ & $12(66.7)$ & 0.507 \\
\hline $21-30$ & $41(54.7)$ & $34(45.3)$ & & $22(29.3)$ & $60(70.7)$ & \\
\hline $31-40$ & $17(25.8)$ & $49(74.2)$ & & $14(21.2)$ & $58(78.2)$ & \\
\hline$\geq 41$ & $0(0.0)$ & $2(100.0)$ & & $0(0.0)$ & $3(100.0)$ & \\
\hline \multicolumn{7}{|l|}{ Education level } \\
\hline No education & $0(0.0)$ & $11(100)$ & 0.002 & $0(0.0)$ & $11(100.0)$ & 0.001 \\
\hline Primary education & $49(39.2)$ & $76(60.8)$ & & $20(16)$ & $105(84)$ & \\
\hline Secondary education & $15(60.0)$ & $10(40.0)$ & & $8(32.0)$ & $17(68)$ & \\
\hline \multicolumn{7}{|l|}{ Marital status } \\
\hline Married & $34(29.8)$ & $80(70.2)$ & 0.000 & $10(11.9)$ & $74(88.1)$ & 0.000 \\
\hline Single & $26(100)$ & $0(0.0)$ & & $24(92.3)$ & $2(7.7)$ & \\
\hline Separated /Divorced & $4(19.0)$ & $17(81)$ & & $4(19.0)$ & $17(81)$ & \\
\hline \multicolumn{7}{|l|}{ Religion } \\
\hline Catholic & $10(11.9)$ & $74(88.1)$ & 0.000 & $10(11.9)$ & $74(88.1)$ & 0.000 \\
\hline Protestant & $11(61.1)$ & $7(38.9)$ & & $11(61.1)$ & $7(38.9)$ & \\
\hline Muslim & $0(0.0)$ & $12(100)$ & & $0(0.0)$ & $12(100)$ & \\
\hline Seventh Day Adventist & $43(91.5)$ & $4(8.5)$ & & $21(44.7)$ & $26(55.3)$ & \\
\hline \multicolumn{7}{|l|}{ Wife's occupation } \\
\hline Farmer & $42(44.2)$ & $53(55.8)$ & 0.002 & $22(23.2)$ & $73(76.8)$ & 0.004 \\
\hline State / private employment & $4(100.0)$ & $0(0.0)$ & & $4(100.0)$ & $0(0.0)$ & \\
\hline Self employed & $0(0.0)$ & $11(100)$ & & $0(0.0)$ & $11(100)$ & \\
\hline Household & $14(38.9)$ & $22(61.1)$ & & $12(33.3)$ & $24(66.7)$ & \\
\hline Not employed & $4(26.7)$ & $11(73.3)$ & & $4(26.7)$ & $11(73.3)$ & \\
\hline \multicolumn{7}{|l|}{ Husband's occupation } \\
\hline Farmer & $49(43.4)$ & 64(56.6) & 0.014 & $29(25.7)$ & $84(74.3)$ & 0.146 \\
\hline State / private employment & $4(15.4)$ & $22(84.6)$ & & $4(15.4)$ & $22(84.6)$ & \\
\hline Self employed & $11(50)$ & $11(50.0)$ & & $9(40.9)$ & $13(59.1)$ & \\
\hline \multicolumn{7}{|l|}{ ANC visits } \\
\hline 0 & $1(0.0)$ & $14(100)$ & $<0.001$ & $1(6.7)$ & $14(93.3)$ & $<0.001$ \\
\hline 1 & $2(6.9 \%)$ & $27(93.1)$ & & $0(0.0)$ & $29(100)$ & \\
\hline $2-3$ & $50(50.0)$ & $54(50.0)$ & & $30(28.8)$ & $74(71.8)$ & \\
\hline$\geq 4$ & $11(92.3)$ & $2(7.7)$ & & $12(92.3)$ & $1(7.7)$ & \\
\hline
\end{tabular}

A bivariate analysis was conducted to assess the association between independent variables and mothers' knowledge and practice of neonatal hypothermia, as presented in Table 5. Bivariate analysis indicated statistical significance with socio-demographic variables age $(p=0.002)$, level of education $(p=0.002)$, marital status $(p=0.000)$, religion of participants $(p=0.000)$, father's occupation ( $p=0.014)$ mother's occupation $(p=0.002)$, and number of ANC attendance $(p<0.001)$.

All variables were significantly associated with the level of knowledge ( $\mathrm{p}$-value $<0.05$ ). Regarding practice variables, educational level $(\mathrm{p}=0.001)$, marital status $(\mathrm{p}=0.000)$ religion of participants $(p=0.000)$, mothers' occupation $(p=0.004)$, and ANC attendance $(p<0.001)$ were statistically significant with mother's level of practice. There was no statistical significance identified for age $(p=0.507)$, and father's occupation $(p=0.146)$, with $p$-value $>0.05$. 


\section{Multiple logistic regression of variables that have effect on knowledge and practice about hypothermia in newborn.}

Table 6. Multiple logistic regression demographic variables on knowledge and practice of neonatal hypothermia

\begin{tabular}{|c|c|c|c|c|c|c|}
\hline \multirow[b]{2}{*}{ Variables } & \multicolumn{2}{|c|}{ Knowledge } & \multirow[b]{2}{*}{$\mathbf{p}$} & \multicolumn{2}{|r|}{ Practice } & \multirow[b]{2}{*}{$\mathbf{p}$} \\
\hline & OR & 95\% CI & & OR & $95 \% \mathrm{CI}$ & \\
\hline \multicolumn{7}{|l|}{ Age (years) } \\
\hline $21-30$ & 0.942 & $0.778-1.686$ & 0.093 & 1.059 & $0.882-1.389$ & 0.265 \\
\hline $31-40$ & 1.262 & $0.973-1.786$ & 0.078 & 1.102 & $0.998-1.440$ & 0.110 \\
\hline$\geq 41$ & 1.567 & $1.211-1.985$ & 0.067 & 1.265 & $1.110-1.562$ & 0.124 \\
\hline \multicolumn{7}{|l|}{ Education } \\
\hline Primary school & 1.061 & $0.872-1.676$ & 0.058 & 1.162 & $0.971-1.971$ & 0.113 \\
\hline Secondary school & 1.787 & $1.521-2.187$ & 0.032 & 1.987 & $1.722-2.689$ & 0.037 \\
\hline \multicolumn{7}{|l|}{ Marital status } \\
\hline Single & 1.474 & $0.988-1.785$ & 0.122 & 1.273 & $0.818-1.375$ & 0.322 \\
\hline Separated / Divorced & 1.168 & $0.893-1.687$ & 0.231 & 0.964 & $0.593-1.797$ & 0.222 \\
\hline \multicolumn{7}{|l|}{ Religion } \\
\hline Protestant & 1.261 & $0.834-1.984$ & 0.433 & 1.162 & $0.731-1.881$ & 0.073 \\
\hline Adventist & 1.112 & $1.081-2.111$ & 0.211 & 0.742 & $0.501-1.611$ & 0.112 \\
\hline Muslim & 0.978 & $0.921-1.911$ & 0.321 & 1.278 & $0.721-1.813$ & 0.061 \\
\hline \multicolumn{7}{|l|}{ Husband's occupation } \\
\hline State and private & 1.576 & $1.021-2.006$ & 0.133 & 1.051 & $0.826-1.771$ & 0.784 \\
\hline Self employed & 1.376 & $1.121-2.123$ & 0.231 & 1.432 & $0.960-1.986$ & 0.938 \\
\hline \multicolumn{7}{|c|}{ Attendant's occupation } \\
\hline State and private & 1.062 & $0.978-1.731$ & 0.784 & 1.176 & $0.778-1.632$ & 0.894 \\
\hline Self employed & 0.932 & $0.795-2.001$ & 0.334 & 0.942 & $0.595-1.611$ & 0.223 \\
\hline Household & 0.818 & $0.613-1.586$ & 0.422 & 0.731 & $0.413-1.382$ & 0.123 \\
\hline Students & 1.386 & $0.934-1.675$ & 0.483 & 1.102 & $0.724-1.574$ & 0.643 \\
\hline \multicolumn{7}{|l|}{ ANC visits } \\
\hline 1 & 1.553 & $1.112-1.876$ & 0.543 & 0.953 & $0.413-1.316$ & 0.212 \\
\hline $2-3$ & 1.518 & $1.211-1.936$ & 0.053 & 1.317 & $0.912-1.731$ & 0.323 \\
\hline$\geq 4$ & 1.884 & $1.675-2.565$ & 0.042 & 1.281 & $1.072-1.664$ & 0.432 \\
\hline
\end{tabular}

Variables, which show significant association with the dependent variable, were recruited to multiple logistic regressions to identify their effects on knowledge and practice of hypothermia in the newborn (Table 6). The results have shown that those who completed secondary school were more knowledgeable than those who reported being illiterate $(\mathrm{OR}=1.787, \mathrm{p}=0.032,95 \%$ $\mathrm{CI}=1.521-2.187$ ). Participants who attended ANC four times or more were nearly two times more likely to be knowledgeable than those who did not attend $(\mathrm{OR}=1.884, \mathrm{p}=0.042,95 \% \mathrm{CI}=1.675$ 2.565). Regarding practice, the results have shown that those who completed secondary school were more acquainted with practice than those who reported being illiterate $(\mathrm{OR}=1.787$, $\mathrm{p}=0.032,95 \% \mathrm{CI}=1.521-2.187)$. 


\section{DISCUSSION}

\section{Sociodemographic characteristics}

This study aimed to assess knowledge and practices of neonatal hypothermia at a selected provincial hospital. The majority of participants $(46.6 \%)$ were aged 21-30 years, and another (41\%) were aged 3140 years. This finding signifies that the large majority of participants were proficient in terms of childbearing process and hence aware of newborns management. Regarding the level of education, the majority $(77.6 \%)$ had a primary school level, and this is contrary to the study conducted at Kenyatta National Hospital where the majority of mothers (48.2\%) had a secondary educational level.[16] Nearly three-quarters $(70.8 \%)$ of mothers in the present study were married, which is similar to other studies.[16,17]

Marital status has long been identified as a significant predictor for newborn health improvement; this is supported by a study done in Bangladesh highlighting the role of men in increasing mothers' knowledge in terms of neonatal danger signs, including hypothermia.[11] Concerning the mother's occupation, more than half $(59 \%)$ were farmers. This may have a positive impact on neonates whose mothers are self-employed or farmers, as a study conducted in Northern India reported that the risk of neonates having hypothermia was minimal for mothers who were working as farmers, staying at home, or selfemployed, compared to those working in the private sector.[18]

\section{Mothers' knowledge regarding neonatal hypothermia}

Neonatal hypothermia has been identified as a lifethreatening situation for neonatal survival, but less attention has been given to this health challenge, notably in resource-limited settings; mothers remain unknowledgeable. Although more than half $(58 \%)$ of mothers reported having received information on thermal care, nearly all, 97\% had inadequate knowledge. This finding is similar to a crosssectional study done in Kenya that classified mother's knowledge of neonatal hypothermia to be low [16]. Furthermore, the majority (73\%) of mothers reported to recognize hypothermia by simple touch; which is inconsistent with the WHO which defines hypothermia as a core body temperature (axillary) less than $36.5^{\circ} \mathrm{C}$ using a digital thermometer.[9]

In this study, the meaning of neonatal hypothermia was reported by $(26.7 \%)$ of participants, and this equates to the most neglected danger sign affecting the neonate. A study conducted on awareness and knowledge of newborn dangers signs among delivered mothers found that only $4 \%$ of them were knowledgeable about neonatal hypothermia.[18] Similarly, a study conducted in Bangladesh found that $(51.4 \%)$ of mothers recognized hyperthermia as more dangerous, whereas only $(26.1 \%)$ reported hypothermia as a risk.[11]

What is known about hypothermia, it is mostly associated with worsening conditions that are known to kill neonates, such as prematurity, sepsis and birth asphyxia. This misclassification leads to negligence.[5] Mothers knew the classic causes of newborn heat loss; whereas bathing at birth and allowing the baby to lie alone was still a challenge, with $(38.5 \%)$ and $(39 \%)$ of participants, respectively. This finding is consistent with a study conducted in Dhaka, Bangladesh, where all neonates were cleaned at birth to remove childbearing odors.[3]

Furthermore, in Zambia, neonates were bathed at birth and kept away from the mother until she recovers.[3] This study showed that (77.6\%) of mothers recognized that hypothermia leads to death; while dyspnea was known only by $(37.3 \%)$, and other complications were not reported. This finding is consistent with the literature concerning hypothermia whereby other authors argue it is a silent killer for neonates.[17] Dyspnea was also unclear as a classification of a danger sign by the WHO though present in most serious illnesses, rather than a complication; this situation will also confuse mothers.[9]

Although mothers received information about neonatal hypothermia from nurses, the problem is to ensure the accuracy of information. A study in Nepal similarly argued that the knowledge and practice of mothers regarding neonatal hypothermia depend mainly on the quality of the received message.[19]

Skin-to-skin contact and early breastfeeding were only reported by $(6 \%)$, and $(12 \%)$, respectively, yet this knowledge and practice should be shared with all mothers immediately after birth, even to those who had a caesarean birth. This finding indicates that SSC and breastfeeding were unrecognized as heat producers and hence inconsistent with the WHO chain of warmth that includes SSC/KMC and breastfeeding as ways to prevent heat loss in neonates.[9] Therefore, encouraging early breastfeeding in preventing neonatal hypothermia is vital because hypothermia leads to many other fatal complications such as hypoglycemia, acidosis and even death especially in extremely preterm infants.[20] 


\section{Mothers' practice of neonatal hypothermia}

The majority of our participants (83\%) had poor practice towards thermal care; whereby $(6.2 \%)$ of women had a thermometer, but only $(40 \%)$ of them knew how to use it. Mothers, even educated ones, did not have either the knowledge of how to use a thermometer, or the ability to interpret the numerical findings of a temperature measurement; this is inconsistent with WHO steps for maintaining the chain of warmth that includes temperature measurement.[9] This factor implies that the mother should be initiated consistently to neonatal body temperature measurements. Concerning bathing the baby, (56\%) knew the time of bathing the newborn.

This finding is similar to the context of Tanzania and Ghana were neonates were washed soon after delivery.[13] The WHO recommends postponing a bath at least 24 hours after birth.[9] The majority $(72.7 \%)$ reported the time of drying correctly and wrapping the neonate. This intervention is recommended by the WHO and Dr. Tom Lissauer reported the details of immediate thorough drying, placing the newborn on the mother's chest and covering with a blanket or warm towel is imperative in anticipating neonatal heat loss.[20]

Less than half $(41.4 \%)$ of mothers knew to keep the baby and mother together, which is the best practice to maintain warmth. This finding is inconsistent with a systematic review on hypothermia prevention, assuring that keeping baby and mother together and encouraging breastfeeding is vital in maintaining baby warmth.[1]

The present study found that (61\%) did not know the best practice when mothers did not have enough colostrum. This finding is inconsistent with a study done in Sri Lanka, where (90\%) of postnatal mothers rely on continuous breastfeeding.[5] Similarly, in Ethiopia, the majority of mothers $(85.2 \%)$ had positive behaviors towards breastfeeding as more than half (68.4\%) were aware of exclusive breastfeeding to six months and breastfeeding on demand.[19] In this study, only 39\% of mothers reported not resuming breastfeeding when milk is insufficient; the rest who were economically stable used pre lacteal feeds and sucrose, while the poorest relied on plenty of water.

Even though a large proportion of women breastfeed, not for hypothermia prevention but nutritional purpose; there is a need to spread that information in order to strengthen the use of breastfeeding as a more comfortable, cost-effective way to ensure adequate thermal sustainability, and it remains the best nutrition for the neonate for the first six months. Mothers should be reminded repeatedly that baby suckling is the most affordable fuel for milk production.

Practice of SSC was seemingly low even taught frequently in our health settings; mothers still consider this practice only for preterm neonates. More than half $(54.7 \%)$ of mothers in our study do not know how long a session of the practice of SSC should last. Moreover, KMC should be practiced throughout the day continuously, for health benefits and the growth of the high-risk neonate.[13] Similarly, the WHO viewed KMC as a persistent SSC between the mother and the baby.[6]

Controversially, evidence-based studies assessing knowledge, attitudes, and practices towards the SSC among mothers reported that one-hour session should help accomplish the desired outcomes for neonates.[21] The main observed gap in our study was that nearly all $(96.3 \%)$ mothers did not know the best way to prevent heat loss if the baby was transported at home or for advanced care. This finding is consistent with a study done in India where only (11\%) of mothers observed KMC during transport.[5]

\section{Association of mothers' knowledge, practice and socio demographic characteristics}

Results of the bivariate analysis has shown that variables such as age, level of education, marital status, religion of participants, wife's and husband's occupation, number of ANC attendance were associated with the level of knowledge of hypothermia in the neonate ( $\mathrm{p}$-value $<0.05)$. Multiple logistic regression analysis has shown that the age was not stastically significant; However mothers who completed secondary school were more than one time knowledgeable than those who reported being illiterate $(\mathrm{OR}=1.787, \mathrm{p}=0.032,95 \% \mathrm{CI}=1.521-2.187)$.

This finding is supported by a study done in Kenya that asserted mothers knowledge regarding essential newborn care, including thermal care increased significantly with educational level; those with secondary education were three times more knowledgeable $(\mathrm{OR}=3.3, \mathrm{p}<0.001$, CI 2.0-5.2) with than those with primary education.[16]

ANC attendance in LMIC has been scaled up to eight contacts, and this has had a noticeable impact on positive neonatal outcomes as many health messages are delivered, preferably during pregnancy. In this study, participants who attended 
ANC four times were nearly twice as knowledgeable as those who did not $(\mathrm{OR}=1.884, \mathrm{p}=0.042,95 \%$ $\mathrm{CI}=1.675-2.565)$. Similarly, a study done in Laos argued that mothers' knowledge in terms of newborn care was more enhanced by educational information received at ANC clinics. These findings are in contrast with a study done in Sri Lanka that reported no association between knowledge and ANC attendance.[5] Although this study seemed to contrast many others that strongly recognized ANC education to enhance mother's knowledge, ANC remains a valuable opportunity where mothers acquire knowledge and practices that aim to ensure safe child health. If such gaps are still observed, it is due to negligence or resistance to change. In this study, poor practice was strongly associated with educational level; the results from multiple logistic regressions have shown that those who completed secondary school were nearly two times more likely to have adequate practices than those who reported being illiterate $(\mathrm{OR}=1.987, \mathrm{p}=0.037, \quad \mathrm{CI}=1.722$ 2.689). This finding is supported by a study done in China that highlighted the valuable impact of education in improving health in all areas across nations.[22]

\section{Limitations}

The study has been conducted in one provincial hospital; hence the results cannot be generalized to other hospitals in Rwanda. Recall bias and information bias were possible due to the face-toface technique, asking mother her knowledge or practice, she may have given a perceived desirable response, or with what she does not practice.

\section{CONCLUSION}

Mothers' knowledge and practice of neonatal hypothermia were low in the study population. ANC attendance and educational level appeared to be the main predictors of mothers' knowledge and practice of neonatal hypothermia. ANC attendance has scaled up remarkably; any critical message to mothers should be provided at that level to improve health. Hypothermia is a global burden to neonates regardless of local climate, and an emphasis on observed gaps is needed among mothers. Thus, continuous professional development on prevention should be implemented in midwives and nurses' practice, and these HCPs should share this vital knowledge with mothers. Users must actively observe the WHO chain of warmth, and leaflets should be distributed to all mothers attending maternal child services. Fostering women's education is imperative for enhancing positive neonate outcomes. Qualitative and observational studies among mothers at the community level would assist in further identifying gaps in knowledge and practice of hypothermia and its potential dangers in neonates.

\section{Acknowledgements}

The authors gratefully acknowledge the support of Mrs. Claudine Nshutiyukuri, and significant support from Dr. Pamela Meharry with this manuscript.

\section{Conflict of Interest}

No conflict of interests.

This article is published open access under the Creative Commons Attribution-NonCommercial NoDerivatives (CC BYNC-ND4.0). People can copy and redistribute the article only for noncommercial purposes and as long as they give appropriate credit to the authors. They cannot distribute any modified material obtained by remixing, transforming or building upon this article. See https://creativecommons.org/licenses/by-nc-nd/4.0/

\section{REFERENCES}

1. Mccall E, Alderdice F, Hl H, Vohra S, Johnston L. Interventions to prevent hypothermia at birth in preterm and / or low birth weight infants ( Review ). Cochrane Collab. 2018;98.

2. Demissie BW, Abera BB, Chichiabellu TY. Neonatal hypothermia and associated factors among neonates admitted to neonatal intensive care unit of public hospitals in Addis Ababa , Ethiopia. BMC Pediatr. BMC Pediatrics; 2018;1-10.

3. Lunze K, Yeboah-Antwi K, Marsh DR, Kafwanda SN, Musso A, Semrau K, et al. Prevention and management of neonatal hypothermia in rural Zambia. PLoS One. 2014;9:7.

4. Statistics H. Rwanda Annual Health Statistics Booklet 2014. 2014;

5. Qazi M, Saqib N, Raina R. Knowledge regarding prevention of hypothermia in 
newborns among mothers in Northern India. Int J Res Med Sci. 2019;7:1727-32.

6. Yadav SP, Saund M, Thakur J, Yadav P, Yadav SK, Shah GS. Knowledge, attitude and practices on the care of the newborn in postnatal mothers delivering at a tertiary care centre in Nepal. Sri Lanka Journalof Child Heal. 2016;45:189-92.

7. Shrestha S, Adachi K, Petrini MA, Shrestha S, Rana Khagi B. Development and evaluation of a newborn care education programme in primiparous mothers in Nepal. Midwifery. 2016;42:21-28.

8. Khagi B. Development and Evaluation of a Newborn Care Education Program in Primiparous Mothers in Nepal. Tokyo Metropolitan University; 2016.

9. Sacks E, Moss WJ, Winch PJ, Thuma P, Dijk JH Van, Mullany LC. Skin, thermal and umbilical cord care practices for neonates in southern, rural Zambia: a qualitative study. BMC Pregnancy Childbirth. BMC Pregnancy \& Childbirth; 2015;

10. World Health Organization. Thermal protection of the new born: a practical guide. Safe Mother. Geneva; 1997.

11. Musabyemungu JA, Willson A, Batenhorst S, Webbe J, Cartledge PT. What topics should we teach the parents of admitted neonates in the newborn care unit in the resource-limited setting - a Delphi study. Maternal Health, Neonatology and Perinatology; 2019;1-9.
12. Zaman S Bin, Gupta R Das, Muhammed G, Kibria A, Hossain N. Husband' $s$ involvement with mother' $s$ awareness and knowledge of newborn danger signs in facility - based childbirth settings: a cross - sectional study from rural Bangladesh. BMC Res Notes. BioMed Central; 2018;4-9.

13. Dhanamani, Ebenezer E, Jerone A. Knowledge of Staff Nurses regarding neonatal hypothermia and effectiveness of embrace thermopod in prevention of hypothermia. Indian J Contin Nurs Educ. 18.

14. Urmila K., Ravikumar, Karunakaran U. Study to assess the knowledge, attitude and practice of Kangaroo mother care among post-natal mothers in a tertiary care centre of North Kerala, India. Int $\mathrm{J}$ Contemp Pediatr. 2018;5:992-6.

15. Yamane, T. (1973). Statistics: An introduction analysis. Harper \& Row

16. Lunze K, Yeboah-antwi K, Marsh DR, Kafwanda SN, Musso A, Semrau K, et al. Prevention and Management of Neonatal Hypothermia in Rural Zambia. 2014;9.

17. Polit D, and Beck CT. Manual for nursing research. Generating and assessing Evidence for nursing practice. In: Wolters $\mathrm{K}$, editor. Tenth edit. 1389.

18. Amolo L, Irimu G, Njai D. Knowledge of postnatal mothers on essential newborn care practices at the Kenyatta National Hospital: a cross sectional study.. PANAFRICAN Med J. 2017;8688:1-7. 
19. Gulema H, Berhan D. Level of Knowledge and Associated Factors of Postnatal Mothers , towards Essential Newborn Care Practices at Governmental Health Centers in Addis Ababa, Ethiopia. Hindawi Adv Public Heal. 2018:11.

20. 18. Vilinsky-Redmond A, Sheridan A. Hypothermia in the newborn-an exploration of its cause, effect and prevention. $\mathrm{Br} \mathrm{J}$ Midwifery. 2014;22,:397.

21. Shukla B, Nair A. Study to Assess the Knowledge Regarding Prevention of Hypothermia in Newborns among Postnatal Mothers in Selected Hospital , Jaipur ,. Imp J Interdiscip Res. 2017;Vol-3:530-2.
22. Lissauer T, Fanaroff AA, Miall L, Fanaroff J. Neonatology at aGlance. 3rd ed. Cleveland, Ohio,USA: Wiley-Blackwell; 2016.

23. Abraham Roba A, Binoy S, A Naganuri $M$. Knowledge, Attitude and Practice of Kangaroo Mother Care by Postnatal Mothers who Gave Birth to Preterm and Low Birth Weight Babies in Public Hospitals, Eastern Ethiopia. J Neonatal Biol. 2017;06.

24. Chen Q, Eggleston K, Zhang W, Zhao J, Zhou S. The Educational Gradient in Health in China Qiulin. HHS Public Access. :1-31. 